\title{
Some UK medical schools make the grade
}

The leaders of Britain's medical schools are engaged in an intense round of navel-gazing following a mixed report card on their research efforts that has emerged from a nationwide review of the quality of research in Britain's universities. Organized by the Higher Education Funding Council for England (HEFCE), sixty panels of experts performed the evaluations. Their assessment will be used as the basis for distributing next year's government grants to individual universities through the HEFCE and its three equivalent bodies for Scotland, Wales and Northern Ireland.

Under the so-called Research Assessment Exercise, each university department (or equivalent research unit) was given a score from 1 (low) to 5 (high). In addition, the middle category (3) was divided into two (3a and $3 b$ ), according to the proportion of work considered to be at a national standard. The top category was also divided into two parts (5 and $5^{*}$ ), based on whether the majority or only some of a research unit's "subareas of activity" were judged to be at an international level.

On a positive note, the assessment exercise confirmed that, despite severe pressure on funding over the past decade, Britain still has a large number of university departments and postgraduate institutes carrying out research to a high international standard. Particularly high scores were awarded to a number of specialized London institutes, such as the Institute of Ophthalmology (now part of University College, London), the National Heart and Lung Institute (part of Imperial College), and the Institute of Psychiatry (part of Kings College).

More food for thought, however, is provided by the fact that the proportion of departments considered by the review panels to be operating at an international level in medical science is lower than in some

areas of basic science. For example, only 9 out of 34 institutions evaluated for their research efforts in hospital-based clinical subjects, and 7 out of 32 in clinical laboratory studies, were awarded top marks. In contrast, 12 out of 17 institutions managed to obtain this rating for the research in biochemistry, and 7 out of 15 in pharmacol. ogy.

"In interpreting this result, you have to ask what a clinical school is about," says Keith Peters, Regius professor of Physic at the University of Cambridge. "As well as meeting commitments to teaching and research, as other university departments

Report card grades of top-rated UK research institutions

$5 *$

Institute of Cancer Research (biological clinical laboratory sciences) Univ. of Oxford

(Dunn school of Pathology)

Royal Postgraduate

Medical School

National Heart and Lung Institute (Imperial Coll.) Univ. of Oxford

Institute of Ophthalmology (UCL)

Univ. of Birmingham

Royal Free Hospital School of Medicine \& UCL

Univ. of Liverpool

Univ. of Cambridge

Univ. of Newcastle-upon-Tyne

Univ. of Oxford

Univ. of Leicester

Royal Free Hospital School

of Medicine and UCL Univ. of Cambridge Univ. of Liverpool

of contention. Inevitably it pleases those who were awarded a $5^{*}$, leading them to expect more generous treatment in next year's funding allocation. But the decision is questioned by others on the grounds that scores were based on the average score of an institution or department. "In many instances, the difference between 5 and $5^{*}$ was critically dependent on the size of the bucket," says Peters. "You do not need many people who are not performing as effectively as others to bring the overall score down."

There are other disappointments as well. Some departments saw their rating fall since the last review (in 1992), even though researchers claim there has been little change in their output or performance. There have also been several reports of bitter recrimination where an expected improved score has, despite a concentrated effort, failed to materialize.

In general, however, the assessment exercise has been accepted as fair, particularly as all the members of the reviewing panels enjoyed established research reputations. "No one could argue that these are not distinguished people," says one clinical researcher. Indeed, perhaps the most significant aspect of the Univ. of Oxford

are required to do, it is important to remember that we also have to continue to provide a medical service." Indeed some suggest that, given the fact that this broader commitment is not imposed on basic research disciplines, the panel that reviewed clinical subjects may have been excessively harsh in its judgments, others, that it reflects a continuing need to address barriers to achieving excellence in clinical subjects.

The decision of the funding council to separate the top category into two is a point exercise is its widespread acceptance as a
legitimate basis for selectively distributing university funding. "We are all signed up to the idea of accountability and assessment," says Stephen Tomlinson, dean of the medical school at the University of Manchester. "People are now focusing on the process: are judgements made on appropriate grounds, is the balance right between applied and basic research? This is what we now have to look at."

DAVID DICKSON London, UK 